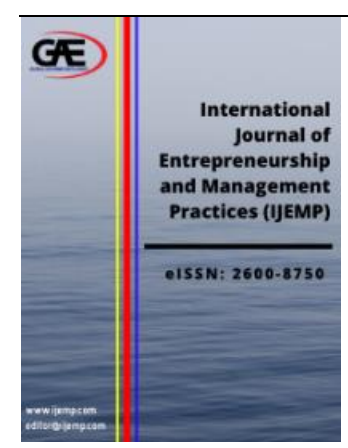

International Journal of Entrepreneurship and Management Practices (IJEMP)

Journal Website: http://ijemp.com/ eISSN: $2600-8750$

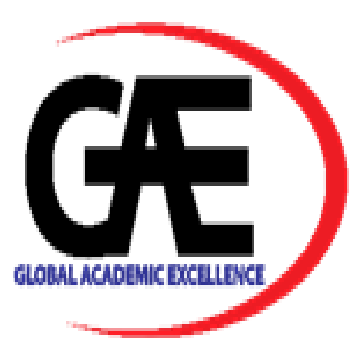

\title{
DOES GOVERNMENT INTERVENTION MODERATE THE EFFECTS OF FINANCIAL LITERACY INTO BUYING MICROINSURANCE AMONG THE MARGINALIZED? A LITERATURE REVIEW
}

Antonio E. Etrata, Jr. ${ }^{1 *}$, Conrado P. Montemayor, Ph.D. ${ }^{2}$

1 The Graduate School, University of Santo Tomas, Manila, Philippines

Email: aeetrata@ust.edu.ph

2 The Graduate School, University of Santo Tomas, Manila, Philippines

Email: cpmontemayor@ust.edu.ph

Corresponding Author

\section{Article Info:}

Article history:

Received date: 26.02 .2020

Revised date: 10.03.2020

Accepted date: 14.03.2020

Published date: 15.03.2020

To cite this document:

Etrata, A. Jr. E., \& Montemayor, C. P. (2020). Does Government Intervention Moderate the Effects of Financial Literacy into Buying Microinsurance among the Marginalized? A Literature Review. International Journal of Entrepreneurship and Management Practices, 3 (9), 42-51.

DOI: $10.35631 /$ IJEMP.39004.

\begin{abstract}
:
Insurance, in general, is considered as one of the most complex products that consumers purchase in their lifetime. Because of its complexities, the insuring public particularly the target of microinsurance which by demographics are considered marginalized, needs to be educated via financial literacy programs. This study explored via literature review the moderating effects of government intervention in cascading awareness and information dissemination through financial literacy programs, the importance of microinsurance as a protective tool against man-made and natural risks. Secondarily, this paper also examined the effects of financial literacy programs in the purchase of microinsurance. It is therefore incumbent upon Governments to ensure that the marginalized, who are considered in dire need of protective mechanisms, to be able to cascade the importance of microinsurance via financial literacy programs.
\end{abstract}

Keywords:

Financial Literacy, Government Intervention, Marginalized, Microinsurance 
In general, insurance is one of the most complex products that a consumer will ever purchase in his lifetime. Its complexity can be associated to its being an intangible product and the intended benefits are futuristic, meaning you will only be able to experience the beauty of being insured once you have qualified under the contractual obligations of the insurance company. Additionally, insurance is viewed as a complicated product as it uses terminologies that are hard to comprehend because of the nature of the jargons used in the insurance contract and the different policies used depending on the nature of risk covered.

These characteristics of insurance products, microinsurance included often lead to scepticism by many clients. This scepticism as to paying for a product that is too complex for them to understand, product offered by a company that they do not trust, and product with future benefits hinders the insuring public from buying a product that will help them in case of unfortunate events, both man-made and natural.

Morelli, et al. (2010) suggests that the success of microinsurance depends on the comprehensibility and understandability by the clients among other conditions.

Because of this, it is incumbent upon insurance providers to properly educate the very market of microinsurance by cascading information and educating them on the need for risk protection through schemes that are affordable to them such as microinsurance and to help them distinguish microinsurance from the traditional insurance products (Siegel et al. 2001).

But why push for microinsurance among other available risk protection mechanisms?

Microinsurance is considered as an important financial product which can help the poor to become sustainable in the event they are exposed to the risks of unforeseen events. In this manner they will not fall into the poverty trap due to the unavailability of a financial tool that will help them cope up with the effects of different risks such as such as health, life, accidents, loss of livelihood, and asset loss.

Morduch (2006) has defined microinsurance as the "next revolution" in addressing the risks and vulnerability faced by the poor in low-income countries as it necessitates the delivery of products that will shield the insured against the occurrence of risk (Makove, 2011).

The post 2015 Millennium Development Goal or the Sustainable Development Goals aim to achieve by 2030 a better and more sustainable future for all. Among the six (6) areas that it seeks to address, poverty has remained the top priority. The United Nations has estimated that as of 2016 , only $45 \%$ of the world's population was effectively covered by at least one social protection cash benefit.

The absence or limitations of social protection programs offered by the Government has made the lives of those at the bottom of the pyramid, those considered marginalized, more prone to poverty trap. This is where microinsurance comes in as it tries to bridge the gap and complement either the absence or limitations of social insurance. The Government should therefore intervene by giving importance to microinsurance in its agenda towards financial inclusion among the marginalized communities. The Government's role is critical in this aspect since policy frameworks and guidelines as regard microinsurance rest upon their regulatory and supervisory powers.

\section{Research Objectives}


The objectives of this paper are the following:

1. To establish the relationship between financial literacy and microinsurance purchase among marginalized.

2. To examine government intervention as a moderating variable in promoting microinsurance among the marginalized.

\section{Methodology}

This research reviews existing literature that highlight the impact of financial literacy programs among target consumers of microinsurance which demographically are considered marginalized. Additionally, related literatures on the role of government were likewise included to justify the significance of government intervention as a moderating variable. The reviewed journals were synthesized, summarized, and presented in this paper.

\section{Literature Review}

\section{Microinsurance}

Microinsurance is an offshoot to microfinance which is primarily aimed at offering insurance products to cover man-made and natural risks. It is specifically designed to meet the requirements of low-income individuals who are not financially able to buy traditional insurance products either because premium is not within their budget or traditional insurance companies consider them within the underwriting restrictions. Its main objective is aligned to making insurance inclusive.

Making insurance more inclusive is in support of the Sustainable Development Goals (SDG) of 2030 which primarily promotes poverty reduction among other equally important goals. In promoting inclusiveness, this means that there needs to be a mechanism that will protect the interests and welfare of the socially excluded members of the society. This mechanism should enable them to mitigate their exposure to risks and cope up with the effects of unfortunate circumstances. Under the impression that they are socially excluded, this intervention should be affordable, the contractual obligations of both the insured and the insurer are non legalistic and lesser technical to make it more understandable to the intended market. Moreover, it should be made accessible to those who are really in dire need of protection. In general, microinsurance is intended for persons disregarded by commercial, traditional and social insurance systems (Churchill, 2007).

But how does microinsurance relate to poverty reduction? There has been a worldwide call to end poverty and use all available means to help achieve SDG 2030. Microinsurance has been proven and noted as a key tool to help the poor, which are considered to be more vulnerable than any sectors in the society, mitigate risks proactively that will enable them to cope up and not to fall in the brink of chronic poverty and vulnerability (Akotey \& Adjasi, 2015; Bakhtiari, 2013, Kishor, 2013). In essence, microinsurance is a solution intended for the poor (Roy, 2015) who lack the financial capacity to cope up with risks such as health related emergencies, death, natural and catastrophic hazards, agricultural risks, accidents and its related shocks (Dror \& Jacquier, 1999, Dercon, 2005). 


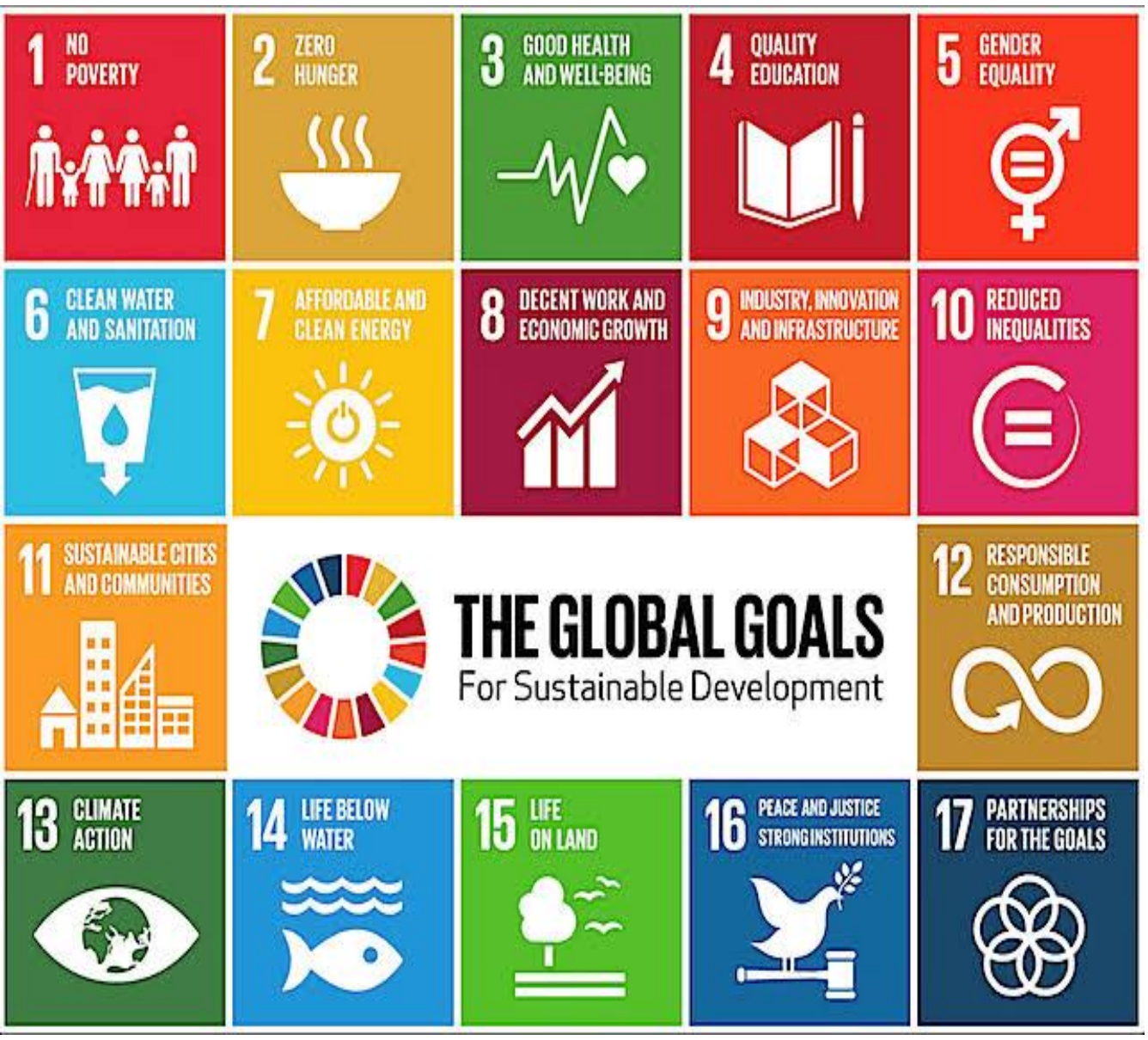

Figure 1: Sustainable Development Goals 2030

Source: United Nations

As a background, the 2030 Agenda for Sustainable Development was adopted in 2015 by all United Nations Member States. It encompasses 17 Sustainable Development Goals (SDGs), which is an urgent call for action for all developed and developing countries to form a global partnership in promoting peace and prosperity for people and the planet, now and into the future. The 17 SDGs which are focused in improving health and education, reduce inequality, and spur economic growth will also pay attention to tackling climate change and working to preserve our oceans and forests. The very heart of this framework recognizes that ending poverty and other deprivations must have effective and efficient strategies.

In a study conducted by the Deutsche Gesellschaft für Internationale Zusammenarbeit in 2017 , the research emphasized the role of inclusive insurance, which is the very purpose of microinsurance, in the achievement of the 11 of 172030 Sustainable Development Goals.

Insurance can be a primary level contributor to 6 SDGs and a secondary level contributor to 6 SDGs (Wanczeck, S., 2017). As a primary level contributor, the effects of insurance to the 6 SDGs namely; (SDG 1) no poverty, (SDG 2) zero hunger, (SDG 3) good health and well being, (SDG 5) gender equality, (SDG 8) decent work and economic growth, and (SDG 13) climate action are direct and its impact on measures governing these 5 SDGs are evident. The relationship of insurance and these 6 SDGs therefore strengthens the framework as illustrated in Figure 3, that insurance mechanism supports the achievement of the enumerated SDGs by providing some form of risk protection for the poor. 


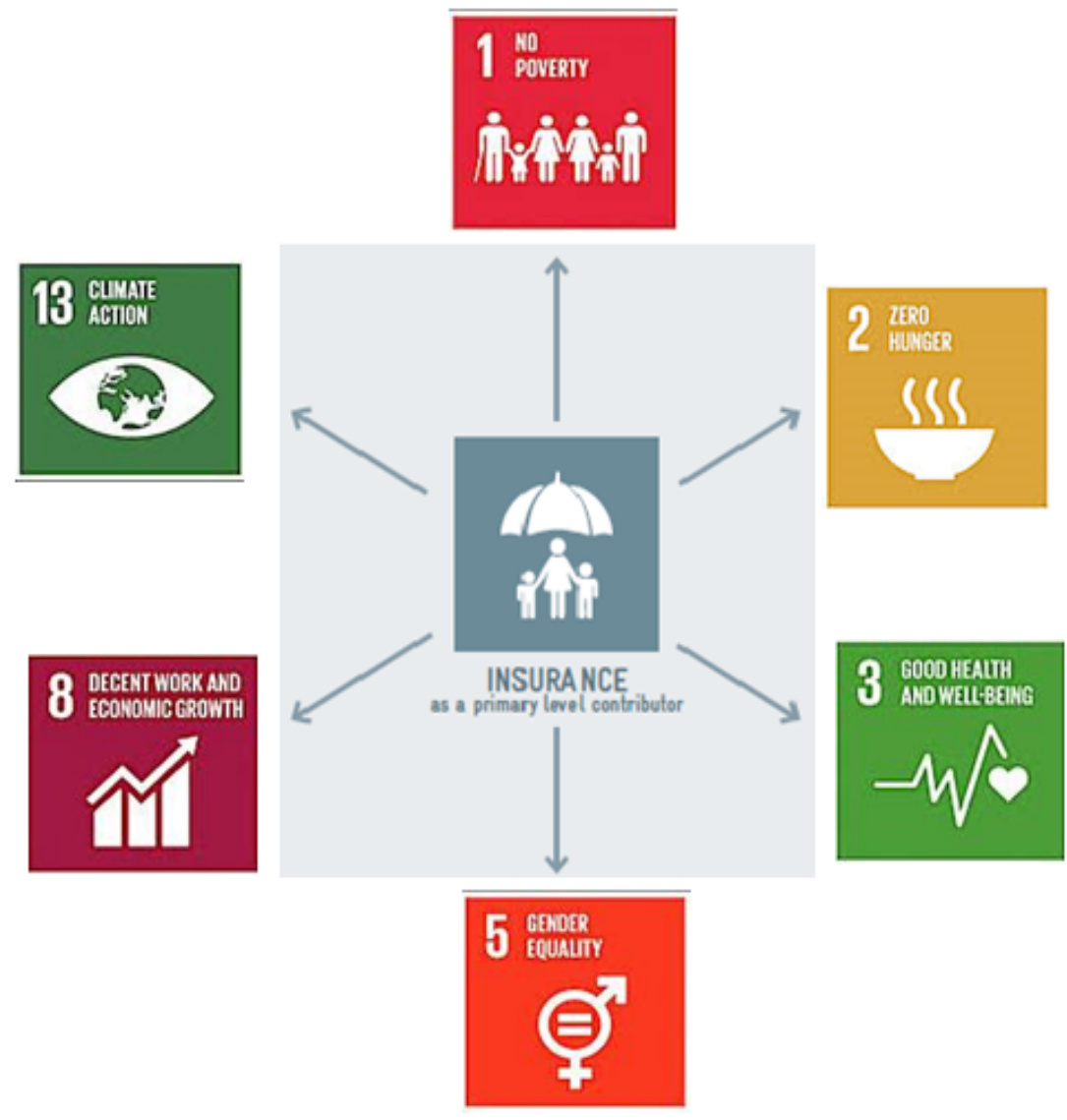

Figure 2: Insurance as a Primary Level Contributor to 6 SDGs

Source: Wanczeck, S., 2017

The main focus of the 2030 SGD is to end poverty, and this has been the primary goal of the Millenium Development Goals (MDG). Insurance has proven time and again that it is a perfect tool in providing mechanisms that will protect people from falling back into poverty once a calamity, man-made or natural, strikes. Without insurance, people will definitely make use of their savings to recuperate that is on the assumption that those affected with unforeseen events have enough savings to start all over again. In the absence of savings, people rely on the benefits guaranteed by an insurance product. However, in the absence of both savings and insurance, people rely from social services which are either none or very limited. The third scenario now leads to people becoming poor or poor people becoming poorer. Insurance therefore provides safety net so that those covered with an insurance product will not use their full savings nor rely fully from government in case calamity strikes. On the other hand, as a secondary level contributor, the effects of insurance to the 5 SDGs namely; (SDG 4) quality education, (SDG 9) industry innovation and infrastructure, (SDG 10) reduced inequalities, (SDG 11) sustainable cities and communities, and (SDG 17) partnerships for the goals, are not evident and obvious. However, insurance remains relevant to these 5 SDGs.

SDG 11 in particular which centers in making cities and communities sustainable. Insurance plays a pivotal role in making SDG 11 realizable by ensuring that human settlements are 
protected making it resilient and sustainable. Lack of insurance clearly exemplifies that people are pushed to a more extreme poverty situation when a catastrophic event happens and there is a need to rebuild human settlements. Effective resilience calls for a risk diversification tool which is one of the major functions of insurance.

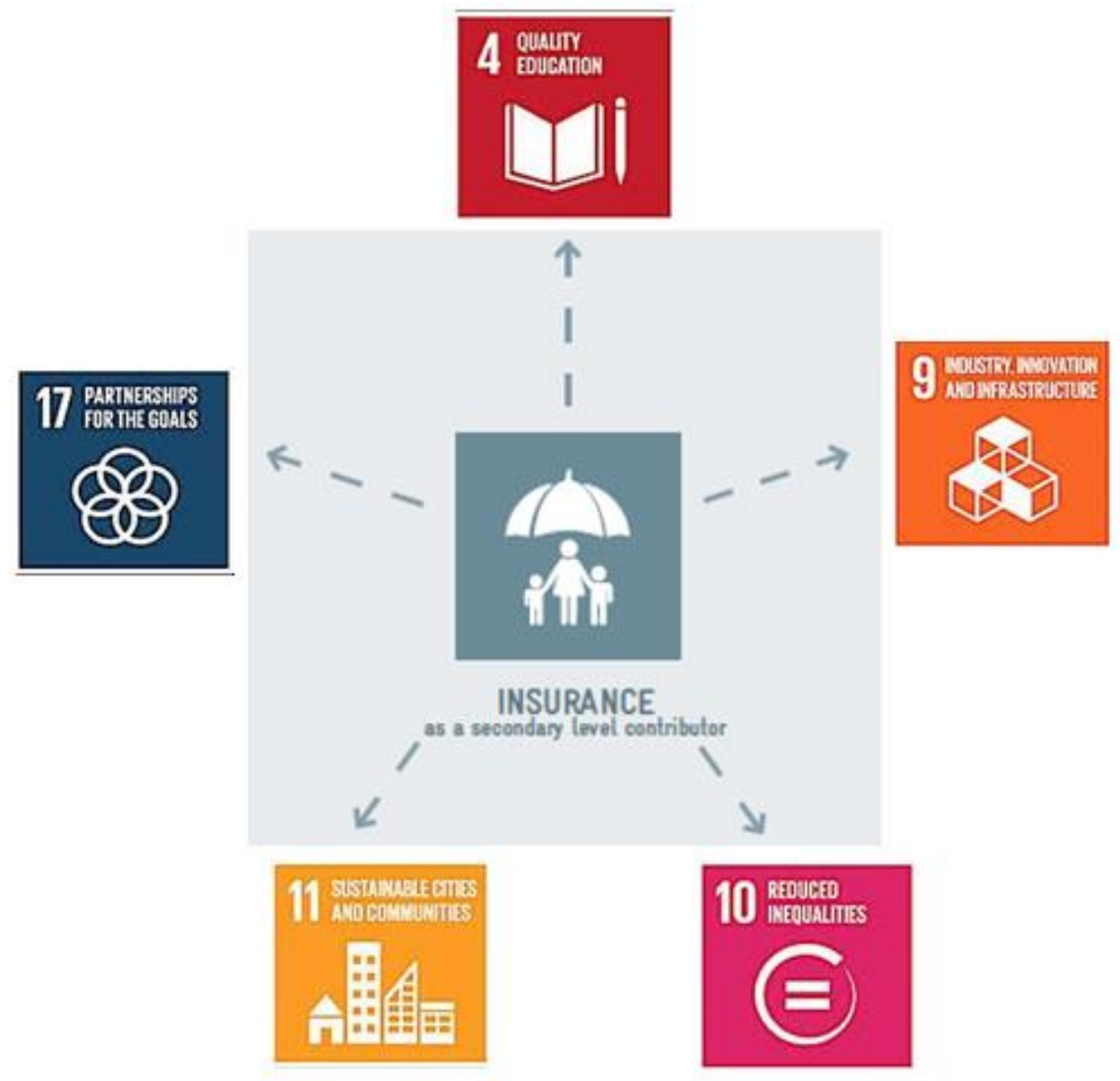

Figure 3: Insurance as a Secondary Level Contributor to 5 SDGs

Source: Wanczeck, S., 2017

Due to the importance of microinsurance, government agencies have joined hands in promoting interventions that helped the microinsurance program gained momentum which resulted in an upward trend in different indicators of the program. Table 1 shows the positive effects in terms of the number of products, number of providers categorization of agents and number of covered individuals.

\section{Financial Literacy}

Tennyson (2011) described insurance is one of the most complex financial products that many consumers purchase in their lifetime. Due to its complexities, informed consumption decisions require consumers to choose an appropriate level of coverage, to understand the policy terms and contractual features, to compare services and financial soundness of competing insurers, and to understand their rights and responsibilities under the contracts (Tennnyson, 2011) in order to come up with a decision to purchase insurance as a tool for risk sharing (Masood, et al. 2015). The study of Tennyson (2011) found that consumers are lacking in insurance knowledge and expressed relatively low level of confidence in their 
insurance decision-making. The results suggest that educational efforts in this area would be beneficial. At individual level, the study found that there is a positive relationship between insurance knowledge and confidence in decisions (Tennyson, 2011).

Uddin (2017) studied the relationship between the influence of insurance literacy on the likelihood of owning a microinsurance policy. It was found that insurance literacy increased the likelihood of having an insurance policy. The enhancement of financial literacy and the personal capabilities of people in financial decision making would improve the financial inclusion outcome and other initiatives as regard poverty reduction. It is a fact that people who are financially literate can demand and properly make use the benefits of financial products such as such as savings, microcredit, and insurance (Refera, et al., 2016) and would significantly impact on the demand for microinsurance products (Asmare, \& Worku, 2018).

Additionally, the importance of financial literacy was highlighted as undoubtedly great in spreading microinsurance awareness. The execution and processes of the insurance system can be realized by improving perception and awareness of people with regard to social insurance (Dalkilic \& Kirkbesoglu, 2015). Ganesh (2015) found that the growing need for financial education for the families to take better financial decision and to increase their economic security has been widely recognized. It is felt that well informed and well educated customers can crate economic ripples. They make better financial decisions for themselves and their families, increasing their economic security and well being. Being financial literate is not only important to the individual household and family, it is also important to communities and societies. Insurance companies can address the problem of financial illiteracy of consumers by educating them. Financial literacy is critical for promoting access to finance by creating incentives and environments that promote desired financial behaviors such as saving, budgeting, or using credit wisely. Having access to savings products or insurance can greatly affect consumers' financial future and are also likely to represent a higher share of income and thus, have significant impact on well being (Kefela, 2010).

When the reasons for low interest on microinsurance explored, it was emerged that people do not understand the concept and mechanism of insurance. In the absence of understandability, people have fewer willingness to to adopt the system of insurance. Low financial literacy has been identified as a barrier preventing the poor from accessing government-supported health insurance programmes (Bauhoff, et al., 2013). It was also revealed that the rather low interest in purchasing insurance is mainly due to misunderstanding the role and necessity of insurance (Ioncica, M. et al., 2012). There is a need to take steps to disseminate knowledge about insurance products and its mechanism through financial literacy training programs (Masood, et al., 2015). Faboyede, et al. (2015), found that promoting financial literacy among Nigerians provides them with the essential knowledge and financial responsibility to make decisions that will better their lives and ultimately grow the economy. Similarly, Cole, et al. (2011), established that households with greater financial literacy were more likely to own insurance policies.

\section{Government Intervention}

In their study conducted in Nigeria, Badru et al. (2013) listed government regulation as one of the factors that influenced the patronage of insurance. The viability of Islamic insurance in particular relies on government intervention and facilitation of the systems to establish policies or regulations that will enable the high uptake of insurance by consumers who are considered low income (Rom \& Ramhan, 2014). Gupta, et al. (2015), emphasized that the government and the non-government organizations should increase their efforts to ensure 
deeper penetration of insurance in the remote areas where the major chunk of population lives below poverty line.

On the part of microinsurance in particular, the Government has a bigger role to perform to support its development (Cole, 2015). It is very important that the government, as part of its regulatory powers, to make certain that microinsurance is congruent to the other social protection programs in place despite the notion that government intervention may be counterintuitive to the usually fierce and independent microinsurance players (Wiechers, 2013). This government intervention guarantees financial stability and consumer protection (Wiechers, 2013) since it is the role of the government to provide financial protection and enhance the quality of life of the poor as part of improving their sustainability (Rom \& Ramhan, 2014).

The importance of the regulatory power of the government in the area of microinsurance as a safety net for the poorest and vulnerable is emphasized in the study of Akter (2012) in Bangladesh which found that the (un)regulatory arrangement on the supply of microinsurance, which excludes accountability and rights of the consumer, will the vulnerability of the poor. This explains the power of Government's intervention in so far as policy formulation and regulatory function in insurance in general and microinsurance in particular, to promote and align the same as a social protection mechanism intended for the poor and the vulnerable. This is so because governments across nations are becoming more aware that as insurance is not universal it has excluded those who should be socially covered with risk intervention tools (Green \& Penning-rowsell, 2004). The government is likewise required to take part in a key leadership role in areas such as providing data to be used to develop legal and regulatory frameworks that will enable the private sector to be more innovative and achieve insurance penetration (World Bank, 2005).

The Government is strongly urged to make use of financial literacy via educational programs particularly the use of mass media since it was revealed in the study that the creation of awareness has significantly reflected in the lives of the insuring public (Ajemunigbohun et al., 2015).

Moreover, because of the inability of both microinsurance and social protection to stand alone to be sustainable and more efficient in its desire to reach the excluded segment of the population, the Government must link microinsurance and other social protection components in the national social protection strategies in order to make a developmentally rational, consistent, well-organized and equitable system (Jacquier et al., 2006).

\section{Conceptual Framework}

The research framework explains the relationship of the variables considered in this study as a result of the review of related literature.

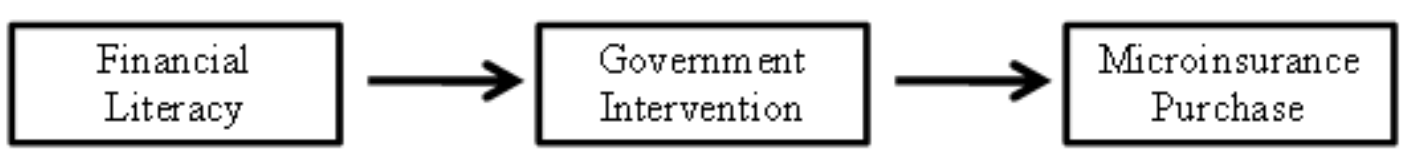

Figure 4: The Conceptual Framework 
Figure 4 shows the relationship between the variables of this study. Financial literacy is the independent variable and microinsurance purchase is the dependent variable. Government intervention is a moderating variable which explains the causal relationship between the independent and dependent variables.

The conceptual framework would like to validate whether or not government intervention positively influences the promotion of microinsurance among the marginalized through financial literacy programs. The reviewed literature stressed the major role of the government in propagating awareness by conducting financial literacy programs aimed at educating those in the lower socio-economic class who are considered marginalized.

\section{Conclusion}

The value of financial literacy as regards to increasing the level of microinsurance awareness of communities considered as marginalized cannot be sidelined. Increasing the level financial literacy among marginalized communities is an effective tool to inform them of the benefits of owning a microinsurance policy which can be used in the event of unforeseen and unfortunate circumstances. These lists of covered risks however should be evidently enumerated in the policy and clearly understood by the policy holder. The level of understanding deeply depends on how financial literacy programs have addressed the level of insurance awareness.

Furthermore, it is incumbent upon the Government to help private insurance companies in the pursuit of information dissemination since it is within their duty as part of implementing poverty reduction programs to attain the objectives of the Sustainable Development Goals of 2030.

\section{References}

Ajemunigbohun, S. S., Oreshile, A. S. \& Iyun, A. S. (2015). An Exploratory study of the awareness and accessibility of Microinsurance products in selected insurance companies in Lagos, Nigeria. British Journal of Economics, Management \& Trade, 5(2), 153-163.

Asmare, A. \& Worku, A. (2018). Determinants of microinsurance demand in Jimma zone. International Research Journal of Business Studies, 11 (3).

Bauhoff, S., Carman, K.G. \& Wupperman, A. (2013). Financial literacy and consumer choice of health insurance. RAND Working Paper No. 113. Santa Monica, CA: RAND Corporation.

Cole, S., Sampson, T. \& Zia, B. (2011). 'Prices or knowledge? What drives demand for financial services in emerging markets?'. The Journal of Finance, 66 (6), 1933-1967.

Dalkilic, N. \& Kirkbesoglu, E. (2015). The role of financial literacy on the development of insurance awareness. International Journal of Economics and Finance, 7 (8), 272280.

Faboyede, O., Ben-Caleb, E., Oyewo, B., \& Faboyede, A. (2015). Financial literacy education: key to poverty alleviation and national development in Nigeria. European Journal Accounting Auditing and Finance Research , 3 (1), 20-29.

Ganesh, A. (2015). Insurance awareness of India. International Journal of Applied Research, 1 (9), 100-103.

Gupta, P. K., Venkataramani, B., Singh, A. S. \& Ambarkhane D. (2015). Challenges of effective implementation of microinsurance in India: A case study of Bhartiya Agro Industries Foundation (BAIF). Annual Research Journal of Symbiosis Centre for Management Studies, Pune, 3, pp. 176-187. 
Ioncica, M., Petrescu, E. C., Ioncia, M. C. (2012). The role of education on consumer behavior on the insurance market. Social and Behavioral Sciences, 46, 4154-4158.

Kefela, G. (2010). Promoting access to finance by empowering consumers Financial literacy in developing countries. Educational Research and Reviews, 5 (5), 205-212.

Makove, S. M. (2011). African Policy Approaches: Microinsurance in Kenya. AIO - A2ii Regulators' Workshop, Victoria Falls, Zimbabwe May 26, 2011.

Masood, S. Q. (2015). Microinsurance and education: How to make it success. Science International, 27 (1), 423-430.

Morelli, E., Onnis, G.A., Ammann, W.J., \& Sutter, C. (2010). Microinsurance: An Innovative Tool for Risk and Disaster Management. Switzerland: Buchdruckerei Davos AG.

Refera, M. D. (2016). Financial literacy for developing countries in Africa: A review of concept, significance and research opportunities. Journal of African Studies and Development , 8 (1), 1-12.

Siegel, P. A. (2001). Viewing microinsurance as a risk Management tool. Social protection discussion paper No. 2001. Washington, DC: The World Bank.

Tennyson, S. (2011). Consumers' insurance literacy: evidence from survey data. Financial Services Review, 20 (3), 165-179.

Uddin, M. A. (2017). Microinsurance in India: Insurance literacy and demand. Business and Economic Horizons, 13 (2), 182-191.

Wanczeck, S. McCord, M, Wiedmaier-Pfister, M., \& Biese, K. (2017). Inclusive

Insurance and the Sustainable Development Goals. Deutsche Gesellschaft für Internationale Zusammenarbeit 